\title{
Diagnostic modalities $x-r a y$ and CT chest differ in the management of thoracic injury
}

\author{
Chapagain $D^{1}$, Reddy DJ ${ }^{2}$, Shah $\mathrm{S}^{3}$, Shrestha KG ${ }^{3}$
}

MS, M.Ch.(CTVS) ${ }^{1}$, Professor and HOD (CTVS) ${ }^{2}$, M.Ch. Resident(CTVS) ${ }^{3}$. Department of Cardiothoracic and Vascular Surgery., College of Medical Sciences, Teaching Hospital, Bharatpur, Chitwan, Nepal.

\section{ABSTRACT \\ Objective:}

To observe difference in the management of blunt trauma to the chest on the basis of conventional $x$ ray and computerised tomography of the chest.

\section{Methods:}

This prospective study was conducted between December 2011 to October 2012 in COMS in Bharatpur,a tertiary referral centre in central Nepal . Clinically stable thoracic injury patients were first evaluated with chest $\mathrm{x}$-ray and the management on this basis was recorded. The findings of the CT chest were assessed and the type of management on the basis of CT was also recorded. Outcome was assessed in terms of mortality, morbidity, hospital and ICU stay with respect to the management on the basis of chest x-ray and CT scan.

\section{Results:}

Of the 129 patients, $74.4 \%$ were male and $25.6 \%$ were female with the patients ranging in age from 7 to 87 years (mean $=40.41$ years). The most common mechanism of trauma to the chest was as a result of a motor vehicle accident $(69.8 \%)$, followed by fall injury $(20.2 \%)$. X-ray chest diagnosed rib fracture in $62 \%$, haemothorax in $37 \%$, pneumothorax in $27 \%$, lung contusion in $10 \%$ and haemopneumothorax in $21 \%$ patients. Similarly CT chest diagnosed rib fracture in $86 \%$, haemothorax in $54 \%$, pneumothorax in $36 \%$, lung contusion in $30 \%$ and haemopneumothorax in $30 \%$ patients. Mean hospital stay was 9.5 days in the group of patients having management on the basis of $x$-ray chest relative to mean stay of 10.2 days in the CT- chest group. In the management on the basis of $x$ ray group, there was a mean ICU stay of 2.8 days compared to mean stays of 3.2 days in CT chest group.

\section{Conclusion:}

Though CT scan of the chest is more informative and differs the management of the blunt chest trauma, one should not forget to advise the cost effective, easily available and initial guiding agent, $x$ ray chest for early management of the chest injury patient.

Key words: X-ray chest, CT-scan, patient management.

Correspondence: Dr. Dinesh Chapagain

E-mail: doc_chapagain@yahoo.com 
Chapagain et al. Diagnostic modalities $x$-ray and..........

\section{INTRODUCTION}

History and physical examination is the most important tool for the initial approach in the diagnosis of injury. Regarding the chest injury, expeditious inspection and palpation of the chest will provide much information about the patient's injuries. Auscultation of the chest should be focused on the symmetry and the presence of air entry. Thoracic percussion may be difficult to interpret in the initial stage of minimal haemothorax and with surgical emphysema. The usual diagnostic workup in the emergency department for blunt injuries to the chest includes a routine chest X-ray. Though this approach is very informative regarding management, significant injuries, such as fracture bony cage, pneumothoraces, haemothoraces, and lung contusions may be missed during the initial trauma assessment.Another investigation that is relevant to assess blunt trauma to the chest is computed tomography (CT) scanning. CT scanning is accurate in visualising intrathoracic injuries, such as fractures, pneumothoraces, haemothoraces, lung contusions, injury to mediastinal structure, diaphragmatic and other abdominal structure in vicinity to the chest like spleen and liver. Though costly, the availability and reliability has led to its widespread use in the evaluation of blunt trauma. This will help to guide decisions about the further investigation and management of blunt trauma to the chest.

\section{MATERIALS AND METHODS}

This prospective study was done in College of Medical Sciences, Bharatpur Chitwan between December 2011 to October 2012. In the emergency department, doctor/resident on duty first assessed the victims.
Patients presenting with hypotension, massive blood loss, or disabling dyspnoea were evaluated immediately and resuscitated accordingly. Clinically stable thoracic injury patients were first evaluated with chest $\mathrm{X}$-ray. The findings of the chest x-ray like pneumothorax, haemothorax, haemopneumothorax, lung contusion, bony fractures (ribs, sternum and thoracic vertebra) and other thoracic injury were recorded. The type of management provided to the patients with the assessment of the X-ray chest were recorded. CT scan of the chest was done either immediately when reaching the hospital or later with in 24 hours of admission in a clinically stable patients. The finding of the CT chest were assessed. The type of management done on the basis of CT was recorded. The length of hospital stay and ICU stay were recorded. The pathological findings of CT scan were taken as a control relative to the chest X-ray finding and was considered to have provided additional information compared with the chest X-ray alone. Chest-tube insertion was performed in patients with pleural complications and in those with extensive subcutaneous emphysema and prominent dyspnoea, even if there was no evidence of pneumothorax in the chest X-ray as this could be life saving procedure. Thoracotomy was performed if there was evidence of continuous bleeding and persistent air leak. Other associated injuries were also recorded. Outcome was assessed in terms of mortality,morbidity,hospital and ICU stay in respect with the management seeing the chest $\mathrm{X}$-ray and CT scan. Data was analysed with the help of SPSS software version 12. Data was summarized in form of proportions and frequency tables for categorical variables. Chi-square test was used to test for significance of associations between the predictor and outcome variables in the categorical data. 


\section{RESULTS}

Of the 129 patients, $74.4 \%$ were males and $25.6 \%$ were females with the patients ranging in age from 7 to 87 years $($ mean $=40.41$ years $)$ with standard deviation of 17.71 years (Table1). The most common mechanism of trauma to the chest was as a result of a motor vehicle accident (69.8\%) followed by fall injury (20.2\%) (Table2). As shown in table 3, $86 \%$ had rib fracture diagnosed by $\mathrm{CT}$ chest in which $61 \%$ had positive finding in $\mathrm{x}$-ray chest $(\mathrm{p}$-value $=0.015)$ table $3 . \mathrm{CT}$ chest diagnosed $54 \%$ of haemothorax but only $37 \%$ of haemothorax were diagnosed by conventional chest $\mathrm{x}$-ray $(\mathrm{p}$-value $=0.00)$. Thirty six percent of patients had pneumothorax diagnosed by CT and $27 \%$ of patients were diagnosed by x-ray ( $p$-value-0.000). Twenty one percent of haemopneumothorax were diagnosed by $\mathrm{x}$-ray chest but $\mathrm{CT}$ chest diagnosed in $30 \%$ of cases ( $\mathrm{p}$-value- 0.000 ). Thirty percent of lung contusions were diagnosed by CT chest but only 10 percent of cases were diagnosed by $x$-ray chest ( $p$ value-0.000). Seven percent of patients had flial chest. Other bony fractures like clavicular fracture $(21.7 \%)$, sternal fracture (3.1\%), scapular fracture (5.4\%) were seen. Myocardial injury (2.3\%), brachial plexus injury $(2.3 \%)$ and diaphragmatic injury $(1.6 \%)$ were observed. Fourteen percent of patients had surgical emphysema.

As Represented by table 5,48 percent had chest tube placed. Five patients had undergone thoracotomy.
Fourty percent tube thoracotomies were managed on the basis of chest X-ray prior to CT scan and an additional Eight percent of the chest tubes were placed after obtaining a $\mathrm{CT}$ chest $\mathrm{scan}(\mathrm{p}$-value $=0.001)$. Seven percent patients required other thoracic procedure like needle decompression and primary wound closure of the chest. Twenty seven percent patients required extrathoracic intervention like abdominal, orthopaedic and neuro surgery. Twelve percent patients did not get any intervention. Two percent patients died of associated head injury. There was no association between the two modalities of investigation in terms of mortality (Table-9).Ninety percent of patients were admitted in the hospital and kept for an average for 8.71 days. A mean hospital stay was 9.5 days relative to of 10.2 days in the CT chest group. Fourty percent of patients needed admission to ICU, where they were kept for an average of 2.27 days. In the management on the basis of $\mathrm{x}$-ray group, there was a mean ICU stay of 2.8days compared to of 3.2 days in CT chest group (Tabel 10). Ten percent patients were kept in ventilator in an average of 0.42 days. As shown in table 6, 15.4\% Fifteen percent patients developed post procedure complication in which most patients $(7.8 \%)$ had residual collection followed by decrease lung expansion(5.4\%).Complications were related with the management on the basis of $x$-ray chest and CT scan of the chest. $(\mathrm{P}=0.002)$ 
Chapagain et al. Diagnostic modalities $x$-ray and..........

Table 1: Descriptive profile of hospital stay of the patient

\begin{tabular}{lccccc|}
$\begin{array}{l}\text { Descriptive } \\
\text { statistics }\end{array}$ & $\begin{array}{c}\text { Age } \\
\text { of } \\
\text { patients }\end{array}$ & $\begin{array}{c}\text { Duration in } \\
\text { ventilator } \\
\text { (Days) }\end{array}$ & $\begin{array}{c}\text { Duration of } \\
\text { ICU } \\
\text { stay(Days) }\end{array}$ & $\begin{array}{c}\text { Duration of } \\
\text { hospital } \\
\text { stay(Days) }\end{array}$ & $\begin{array}{c}\text { Duration of } \\
\text { chest tube } \\
\text { in situ(Days) }\end{array}$ \\
\hline Mean & 40.41 & 0.42 & 2.27 & 8.71 & 2.26 \\
Std. Deviation & 17.716 & 1.345 & 3.349 & 5.956 & 2.461 \\
Minimum & 7 & 0 & 0 & 0 & 0 \\
Maximum & 87 & 6 & 12 & 25 & 10 \\
\hline Total patients & $\mathbf{1 2 9}$ & $\mathbf{1 3 ( 1 0 . 0 1 \% )}$ & $\mathbf{5 2 ( 4 0 . 0 4 \% )}$ & $\mathbf{1 1 7 ( 9 0 . 9 \% )}$ & $\mathbf{6 3}(\mathbf{4 8 . 5 \% )}$
\end{tabular}

Table 2: Mode of injury

\begin{tabular}{lcc|} 
Mode of injury & Number & Percent \\
\hline RTA & 90 & 69.8 \\
\hline Fall injury & 26 & 20.2 \\
\hline Physical assault & 3 & 2.3 \\
\hline Penetrating injury & 6 & 4.7 \\
\hline Bullet injury & 1 & 8 \\
\hline Animal attack & 3 & 2.3 \\
\hline Total & $\mathbf{1 2 9}$ & $\mathbf{1 0 0}$ \\
\hline
\end{tabular}

Table 3: Relation of diagnostic modalities of chest $x$-ray and computed tomography of the chest in the thoracic injury.

\begin{tabular}{lcccc|} 
Disease & CT N(\%) & X-ray N(\%) & Total patients & P-value \\
Pneumothorax & $47(36.43 \%)$ & $36(27.90 \%)$ & 129 & 0.000 \\
Haemothorax & $70(54.26 \%)$ & $46(37.98 \%)$ & 129 & 0.000 \\
Haemopneumothorax & $39(30.23 \%)$ & $28(21.70 \%)$ & 129 & 0.000 \\
Lung Contusion & $39(30.23 \%)$ & $13(10.07 \%)$ & 129 & 0.000 \\
Rib Fracture & $112(86.82 \%)$ & $80(62.01 \%)$ & 129 & 0.015
\end{tabular}


Journal of College of Medical Sciences-Nepal, 2014, Vol-10, No-1

Table-4. Relation in the change of management with computed tomography of the chest

\begin{tabular}{lcccc}
$\begin{array}{l}\text { Management } \\
\text { on the basis of CT } \\
\text { Chest }\end{array}$ & \multicolumn{2}{c}{$\begin{array}{c}\text { Change of } \\
\text { Management }\end{array}$} & Total & $\begin{array}{c}\text { P-value } \\
\text { value }\end{array}$ \\
Yes & $11(8.5 \%)$ & $57(44.1 \%)$ & $68(52.7 \%)$ & $\mathbf{0 . 0 0 1}$ \\
No. & 0 & $61(46.9 \%)$ & $61(46.4 \%)$ & \\
Total & $\mathbf{1 1}(\mathbf{8 . 5 \% )}$ & $\mathbf{1 1 8}(\mathbf{9 1 . 5 \% )}$ & $\mathbf{1 2 9}$ & $\mathbf{0 . 0 0 1}$
\end{tabular}

\section{Table 5: Management of the patients}

\begin{tabular}{lcc} 
Procedure & Number & Percent \\
Tube thoracotomy & 63 & 48.8 \\
Thoracotomy & 5 & 3.9 \\
Other thoracic procedure & 9 & 7.0 \\
Extrathoracic intervention & 36 & 27.9 \\
No intervention & 16 & 12.4 \\
\hline Total & $\mathbf{1 2 9}$ & $\mathbf{1 0 0 . 0}$
\end{tabular}

Table 6: Early complication

\begin{tabular}{lcc|} 
Complication & Number & Percent \\
\hline Pneumonitis & 1 & 0.8 \\
Effusion & 10 & 7.8 \\
Chest deformity & 1 & 0.8 \\
Decrease lung expansion & 7 & 5.4 \\
Lt.phrenic nerve injury & 1 & 0.8 \\
\hline Total & $\mathbf{2 0}$ & $\mathbf{1 5 . 4}$ \\
\hline
\end{tabular}

Table 7: Types of injury

\begin{tabular}{lc} 
Types of injury & Number (\%) \\
Flial chest & $10(7.8)$ \\
Sternal fracture & $4(3.1)$ \\
Myocardial injury & $3(2.3)$ \\
\hline Diaphragmatic injury & $2(1.6)$ \\
\hline Brachial plexus injury & $3(2.3)$ \\
\hline Lung contusion & $39(30.2)$ \\
\hline Scapular fracture & $7(5.4)$ \\
\hline Surgical emphysema & $18(14)$ \\
\hline Pneumothorax & $28(21.7)$ \\
\hline Haemothorax & $70(54.3)$ \\
\hline
\end{tabular}


Chapagain et al. Diagnostic modalities $x$-ray and..........

Table-8: Relation of complication with diagnostic modalities.

\begin{tabular}{|c|c|c|c|c|}
\hline \multirow[t]{2}{*}{ Complication } & \multicolumn{2}{|c|}{$\begin{array}{l}\text { Management on the } \\
\text { basis of CT chest. }\end{array}$} & \multicolumn{2}{|c|}{$\begin{array}{l}\text { Management on the basis } \\
\text { of x-ray chest. }\end{array}$} \\
\hline & Yes & No & Yes & No \\
\hline Yes & 17 & 03 & 11 & 09 \\
\hline No & 51 & 58 & 46 & 63 \\
\hline P-value & \multicolumn{2}{|c|}{0.002} & \multicolumn{2}{|c|}{0.289} \\
\hline
\end{tabular}

Table-9: Relation of mortality with diagnostic modalities

\begin{tabular}{|c|c|c|c|c|}
\hline \multirow[t]{2}{*}{ Mortality } & \multicolumn{2}{|c|}{$\begin{array}{l}\text { Management on the } \\
\text { basis of CT chest. }\end{array}$} & \multicolumn{2}{|c|}{$\begin{array}{l}\text { Management on the basis } \\
\text { of x-ray chest. }\end{array}$} \\
\hline & Yes & No & Yes & No \\
\hline Yes & 02 & 01 & 01 & 02 \\
\hline No & 66 & 60 & 56 & 70 \\
\hline P-value & \multicolumn{2}{|c|}{0.624} & \multicolumn{2}{|c|}{0.702} \\
\hline
\end{tabular}

Table 10: Relation of hospital and ICU stay with the diagnostic modalities.

\begin{tabular}{|c|c|c|c|}
\hline & $X-R a y$ basis & er of patients $(\%)$ & Mean(days) \\
\hline Duration of & Management with x-ray & $57(44.18)$ & 9.54 \\
\hline \multirow[t]{4}{*}{ hospital stay. } & Management other than x-ray & $72(55.81)$ & 8.04 \\
\hline & \multicolumn{2}{|l|}{ CT basis } & \\
\hline & Management with CT & $68(52.71)$ & 10.2 \\
\hline & (Management other than $\mathrm{CT}$ & $61(47.28)$ & 6.0 \\
\hline \multicolumn{4}{|c|}{$X$-Ray basis } \\
\hline Duration of & Management with x-ray & $57(44.18)$ & 2.8 \\
\hline \multirow[t]{4}{*}{ ICU stay. } & Management other than x-ray & $72(55.81)$ & 1.7 \\
\hline & \multicolumn{2}{|l|}{ CT basis } & \\
\hline & Management with CT & $61(47.28)$ & 3.2 \\
\hline & Management other than CT & $68(52.71)$ & 1.1 \\
\hline
\end{tabular}


Journal of College of Medical Sciences-Nepal, 2014, Vol-10, No-1

\section{DISCUSSION}

Injuries of the chest may vary enormously in severity. Younger male populations were the main victims of thoracic injury in this study and mainly due to motor vehicle accident. Overall trauma is the leading cause of death in under 40-year old patients and the third commonest cause of death worldwide. ${ }^{1}$

In routine casualty setting, chest trauma may be caused from a low energy impact are mild to moderately severe to often life threatening in high energy impact mostly due to road traffic accident followed by fall injury.Most of these patients had multiple rib fractures, pneumothorax, haemothorax, haemo-pneumothorax and lung contusion and very few patients had myocardial, thoracic great vessels, oesophageal and diaphragmatic injury. ${ }^{2}$ This profile is in favour of our study.There are difficulties in trying to make a diagnosis in patients with chest trauma. In review of medicolegal cases where radiographic involvement occurred showed that in $55 \%$ of these cases the radiographs were not taken on admission, $23 \%$ clearly missed the abnormality on admission and $10 \%$ were thought to be technically inadequate radiographs. ${ }^{3,4}$

Now days CT scan is readily available in the higher centre. So the routine CT scanning has become more prevalent. Many thoracic injuries, inadequately diagnosed or missed in the conventional x-ray are easily diagnosed by a CT chest. A patient with a relatively minor pneumothorax on chest X-ray who nonetheless develops dyspnea and hypoxia may thus in fact have a significant pneumothorax that is better visualized by CT-chest. In stable patients, CT scanning will also reveal pleural fluid collections and help to distinguish them from parenchymal injury such as pulmonary contusion. Computed tomography (CT) of the chest has become increasingly accepted in the early management of trauma. CT can reveal injuries not seen on initial chest x-ray in about two-thirds of major trauma patients and can lead to therapeutic changes in (5-30)\% of cases. ${ }^{5,6}$ In this study CT chest is very much sensitive in detecting lung contusion followed by haemothorax which was mostly minimal in quantity in the initial phase of the trauma. Lung contusion is a focal parenchymal injury caused by disruption of the capillaries of the alveolar walls and septa, and leakage of blood into the alveolar spaces and interstitium. It's incidence ranges from $17-70 \%$ which is in favour of this study. ${ }^{7} \mathrm{CT}$ is also very sensitive in detecting even a small haemothorax. Haemothorax occurs in $50 \%$ of chest trauma cases, with blood pooling into the pleural space from variable sources: the lung parenchyma, the chest wall, the great vessels, the heart or even the liver and spleen through diaphragmatic rupture. ${ }^{8}$ This is similar to this study.

In this literature, the most common injury is fractured bony cage mostly ribs fracture followed by haemothorax. CT scan is more helpful in diagnosing bony injury of the thoracic bony cage. CT scanning reveal additional findings that are only suggested by an abnormal chest X-ray. CT of the thoracic spine is the "gold-standard" imaging modality for assessing vertebral body as well as posterior element fractures, and is also helpful in imaging the spine at the cervicothoracic junction. ${ }^{9}$

We had seen that significant number of patients of pneumothorax and haemopneumothorax were also detected by CT thorax that was missed by X-ray chest. Trauma-related pneumothorax occurs in $30-40 \%$ of cases,similar to our finding and it is most commonly associated with rib fractures that lacerate the lung and less commonly, caused by a disruption of closed airway spaces, such as the alveoli, due to a sudden increase 
Chapagain et al. Diagnostic modalities $x$-ray and..........

in intrathoracic pressure or to a direct impact or deceleration force to the chest wall. Literature says that $78 \%$ of them are now a days believed to be missed on chest radiograph. ${ }^{10}$

So in this literature, CT scanning of chest was significantly more effective in detecting pneumothoraces and haemopneumothoraces, lung contusions, fractured ribs and mediastinal injury compared to chest X-ray. This is in accordance with several studies that have shown a greater sensitivity for a CT- chest for detecting intrathoracic injuries. ${ }^{11,12}$ Approximately fourty nine percent patients were managed by simple emergency procedure like tube thoracotomy and very few cases had undergone more invasive procedures like thoracotomy and other extra thoracic procedure which is supported by many authors. ${ }^{13}$

Eleven patients needed extra management of tube thoracotomy on the basis of CT chest. The literature mentioned about the better sensitivity of the Computed tomography (CT), four to five times more than the $\mathrm{x}$ ray chest but also mentioned that there is no influence in the patient management and also recommended " No to CT chest" in initial assessment. ${ }^{14,15,16}$

However many literature mentioned that the CT chest is highly sensitive in detecting thoracic injuries after blunt chest trauma and is superior to routine chest Xray in visualizing lung contusions, pneumo- and hemothorax. Early CT chest influences therapeutic management in a considerable subset of patients and also recommended in the primary diagnostic work up of multiple injured patients with suspected chest trauma, because early and exact diagnosis of all thoracic injuries along with sufficient therapeutic consequences may reduce the complications and improve outcome of severely injured patients with blunt chest trauma. ${ }^{17}$ About $70 \%$ cases had undergone change in management in situations where CT-chest were performed, such as insertion or correction of a chest tube, a change in the mode of ventilation, as well as further investigations and/or interventions. ${ }^{18,19,20,21}$

Some other author also wrote that CT detects significant disease in patients with normal initial radiographs and in 20\% will reveal more extensive injuries compared with the abnormal initial radiographs, necessitating a change of management. ${ }^{22}$ The relatively low rate of thoracotomy in this study group might be correlated to a relatively low severity and less patients with penetrating trauma and again supports the fact that most thoracic blunt trauma can be treated conservatively. ${ }^{23}$ Length of hospital stay and ICU stay is related with the type of diagnostic modalities in which CT chest group had longer mean hospital stay which is related with the study done by Ufuk kobanoglu et al. ${ }^{24}$ Three patients died but not related with isolated thoracic injury.These patients had severe head injury. So, mortality is not associated with type of radiological mode of diagnosis but mostly related to other associated polytrauma patients. ${ }^{25}$

Post procedure complication was higher in CT-chest group than $\mathrm{x}$-ray group. This could be because of tube thoracotomy related complication rather than related with types of investigation. Only one patient developed empyema that resolved with repeat tube thoracotomy in effusion group.Majority of patients had minor complication that was resolved with conservative management. This could be because of incompletely drained or prolonged tube placement. ${ }^{26}$ 
Grieser T, Buhne KH, Hauser $\mathrm{H}$ et al: Signifi

\section{CONCLUSION}

The findings from this research highlighted that a CT scan is significantly more likely to yield additional information than a chest X-ray.The clinical history and examination of chest injury patients is, on the whole, unreliable, especially for evaluation of blunt chest trauma. Polytrauma patients if haemodynamically stable, may be benefitted from computed tomography of the chest when therapeutically relevant thoracic injuries are looked for or early therapeutical interventions are checked. However, chest X-ray should stay as a front-line screening method because of its quick feasibility and availability.

\section{REFERENCES}

1 Bone L, Bucholz R. The management of fractures in the patient with multiple trauma. J Bone Joint Surg (Am) 1986; 68: 945.

Trupka A, Nast-Kolb D, Schweiberer L. Thoracic trauma.Unfallchirurg 1998 Apr;101(4):244-58.

3 Chart D, Kraus JF, Riggins RS. Patterns of multiple fracture in accidental injury. J Trauma 1973; 18: 1075

Born CT, Ross SE, Innacone W et al. Delayed identification of skeletal injury in multisystem trauma. The "missed" fracture. Trauma 1989; 29: 1643

5 Guerrero-Lopez F, Vazquez-Mata G, AlcazarRomero PP et al: Evaluation of the utility of computed tomography in the initial assessment of the critical care patient with chest trauma. Crit Care Med 2000; 28:1370. cance of findings of chest $\mathrm{x}$-rays and thoracic CT routinely performed at the emergency unit: 102 patients with multiple trauma. A prospective study. Rofo Fortschr Geb Rontgenstr Neuen Bildgeb Verfahr 2000; 1173:44.

7 Gavelli G, Canini R, Bertaccini P, et al Traumatic injuries: imaging of thoracic injuries. Eur Radiol 2002;12:1273-94.

8 Mirvis SE. Imaging of acute thoracic injury: the advent of MDCT screening. Semin Ultrasound CT MR 2005; 26:305-31.

9 Gray L, Vandemark R, Hays M: Thoracic and lumbar spine trauma. Neuroimaging Clin North Am 2001;11:421.

10 McGillicuddy D. Diagnostic dilemmas and current controversies in blunt chest trauma. Emerg Med Clin North Am 2007;25:695-711.

11 Marts B, Durham R, Shapiro M, et al. Computed tomography in the diagnosis of blunt thoracic injury. Am Surg 1994;168(6):688-92.

12 Wilson D, Voystock JF, Sariego J, et al. Role of computed tomography scan in evaluating the widened mediastinum. Am Surg 1994;60:421-3.

13 Bölükbas S, Ghezel-Ahmadi D, KwozallaAK, et al. Diagnostic assessment and treatment concepts for thoracic trauma.Chirurg 2011 Sep;82(9):843-9.

14 Miller LA. Chest wall, lung, and pleural space trauma. Radiol Clin North Am. 2006 Mar;44(2):213-24. 
15 Poole GV, Morgan DB, Cranston PE, et al. Computed tomography in the management of blunt thoracic trauma. J Trauma 1993;35(2):296300

16 Ordog G J, Balasubramanium S, Wasserberger J. Outpatient management of 357 gunshot wounds to the chest. J Trauma 1983; $23: 832$.

17 Trupka AW, Trautwein K, Waydhas C, et al. Can diagnosis and subsequent trauma management of the multiple trauma patient with blunt thoracic trauma be improved by early computerized tomography of the thorax? Zentralbl Chir 1997;122(8):666-73.

18 Trupka A, Waydhas C, Hallfeldt KK, et al. Value of thoracic computed tomography in the first assessment of severely injured patients with blunt chest trauma: results of a prospective study. J Trauma 1997;43(3):405-11.

19 Omert L, Yeaney WW, Protetch J. Efficacy of thoracic computerized tomography in blunt chest trauma. Am Surg 2001 Jul;67(7):660-4.

20 Guerrero-López F, Vázquez-Mata G, AlcázarRomero PP, et al.Evaluation of the utility of computed tomography in the initial assessment of the critical care patient with chest trauma. Crit Care Med 2000 May;28(5):1370-5.
21 Trupka A, Waydhas C, Hallfeldt KK et al. Value of thoracic computed tomography in the first assessment of severely injured patients with blunt chest trauma: results of a prospective study. J Trauma 1997 Sep;43(3):405-11.

22 Exadaktylos AK, Sclabas G, Schmid SW, et al. Do we really need routine computed tomographic scanning in the primary evaluation of blunt chest trauma in patients with "normal" chest radiograph? J Trauma 2001;51:1173-6.

23 Kulshrestha P, Munshi I, Wait R. Profile of chest trauma in a level I trauma center. J Trauma 2004;57(3):576-81.

24 Ufuk Cobanoglu, Mehmet Melek Yesim Edirne. Chest radiography diagnosis of pulmonary contusion is associated with increased morbidity and mortality. Indian journal of thoracic and cardiovascular surgery 2010; 26( 1): 24-2.

25 Lema MK, Chalya PL, Mabula JB, et al. Pattern and outcome of chest injuries at Bugando Medical Centre in Northwestern Tanzania. Journal of Cardiothoracic Surgery 2011, 6:7.

26 Eddy AC, Luna GK, Copass M .Empyema thoracis in patients undergoing emergent closed tube thoracostomy for thoracic.Am J Surg 1989 May;157(5):494-7. 